\title{
Resolution of chronic migraine headaches with intrathecal ziconotide: a case report
}

\author{
This article was published in the following Dove Press journal: \\ Journal of Pain Research \\ 8 September 2015 \\ Number of times this article has been viewed
}

\section{Sachin Narain' \\ Lama Al-Khoury ${ }^{2}$ \\ Eric Chang ${ }^{3-6}$}

'Department of Anesthesiology and Perioperative Care, ${ }^{2}$ Department of Neurology, ${ }^{3}$ Department of Physical Medicine and Rehabilitation, ${ }^{4}$ Department of Neurosurgery, ${ }^{5}$ Department of Orthopedics, ${ }^{6}$ ReeveIrvine Research Center for Spinal Cord Injury, University of California Irvine, Irvine, CA, USA
Correspondence: Eric Chang

Restore Orthropedics \& Spine Center, I I 20 West La Veta Ave. Suite 300,

Orange, CA 92868, USA

$\mathrm{Tel}+\mathrm{l} 6572104096$

Fax +I 6572104233

Email: echang@restoreorthopedics.com
Background: Migraine headaches are a common and functionally debilitating disorder affecting approximately $17 \%$ of women and $5.6 \%$ of men. Compared to episodic migraine patients, chronic migraineurs are more likely to be occupationally disabled, miss family activities, have comorbid anxiety and/or chronic pain disorders, and utilize significantly more health care dollars. Ziconotide is a calcium channel blocker used for the treatment of chronic severe pain without issues of tolerance or dependency found with opioid therapy.

Case: A 59-year-old female had an intrathecal baclofen pump placed for spasticity secondary to multiple sclerosis. Her symptoms also included lower extremity neuropathic pain and severe migraine headaches with 22 migraine headache days per month. Prior treatments included nonsteroidal anti-inflammatory drugs, triptans, anticonvulsants, antihypertensives, and Botox injections which reduced her symptoms to four migraine days per month at best. While her spasticity had markedly improved with intrathecal baclofen, ziconotide was added to help her neuropathic pain complaints. Following initiation of low-dose ziconotide ( $1 \mu \mathrm{g} /$ day $)$, the patient noted both lower extremity pain improvement and complete resolution of migraine headaches resulting in zero migraine days per month. She has now been migraine free for 8 months.

Conclusion: Upon review of the available literature, there are no published cases of migraine improvement with intrathecal ziconotide. This represents the first case describing resolution of migraine symptoms with low-dose ziconotide.

Keywords: ziconotide, migraine, symptoms, chronic pain, intrathecal pump

\section{Introduction}

Migraine headaches are both a common and functionally debilitating disorder affecting approximately $17 \%$ of women and $5.6 \%$ of men. ${ }^{1}$ Over $50 \%$ of migraine sufferers miss work due to their symptoms. ${ }^{1}$ Migraine headaches can be divided and subdivided into many different categories. One such category is the distinction between episodic and chronic migraine. Patients who have 15 or more headache days per month over a period of 3 months with at least eight of those headaches designated as migrainous (either with or without aura) are considered to be chronic migraine sufferers. ${ }^{2}$

Compared to episodic migraine patients, chronic migraineurs are about twice as likely to be occupationally disabled, ${ }^{3}$ are four times as likely to miss family activities, ${ }^{4}$ utilize four times as many health care dollars, ${ }^{5}$ and are nearly twice as likely to have comorbid anxiety and/or chronic pain disorders. ${ }^{3}$

Therapy is divided into preventive and abortive therapy. Preventive therapy includes antihypertensives, antidepressants, antiepileptics, and supplements - all of which are more effective in treating episodic migraine than chronic migraine. ${ }^{6}$ Abortive treatments 
include triptans, egortamine derivatives, and nonsteroidal anti-inflammatory drugs (NSAIDs). ${ }^{6}$

Procedures such as Botox (Allergan, Irvine, CA, USA) injections are becoming a commonplace preventative therapy for chronic migraine headaches. ${ }^{7}$ While this therapy is beneficial for quite a few patients, many continue to have migraines, albeit with a decrease in frequency and intensity. ${ }^{8}$ However, as many as $38 \%$ of patients may only be partial responders to Botox injections. ${ }^{9}$ This patient population may still be having noticeable discomfort and functional impairment despite these treatments. ${ }^{9}$

Ziconotide (Prialt, Jazz Pharmaceuticals, Dublin, Ireland) is a calcium channel blocker with specificity for the N-type calcium channel. Its favorable properties for the treatment of chronic pain include efficacy against neuropathic pain along with a lack of tolerance and dependency. ${ }^{10}$

Ziconotide has been approved for the management of severe chronic pain in patients for whom intrathecal therapy is warranted and who are intolerant of, or refractory to, other treatments such as systemic analgesics, adjunctive therapies, or intrathecal morphine. Ziconotide must be administered intrathecally via an implanted Medtronic SynchroMed $^{\circledR}$ EL or SynchroMed ${ }^{\circledR}$ II Infusion System, or Simms Deltec CADD Micro ${ }^{\circledR}$ External Microinfusion Device and Catheter. ${ }^{11}$

\section{Case history}

A 59-year-old female with an intrathecal pump (SynchroMed II, Medtronic, Minneapolis, MN, USA) placed for spasticity secondary to multiple sclerosis in 2009 by an outside physician presented to our comprehensive pain clinic for management of her symptoms. She also had a history of peripheral polyneuropathy and pain affecting the legs as well as severe, chronic migraine headache.

She previously had 22 migraine headache days per month for a period greater than 10 years with a history of multiple migraines without aura in the past that began before she was on regular medications for her peripheral polyneuropathy. Her headaches were described as severe, unilateral headaches on the left fronto-temporal area with associated photophobia and phonophobia that incapacitated her and resulted in avoidance of regular daily activity during her severe migraine episodes. She had been evaluated for other headache causes and was given the diagnosis of chronic migraines following an extensive workup by her neurologist.

She previously had tried a variety of abortive medications including NSAIDs and triptans with initial relief but subsequently experienced less benefit. She had also tried a variety of preventative agents including propranolol, candesartan, topiramate, and venlafaxine with minimal benefit before progressing to Botox injections. These injections were done per the PREEMPT treatment plan at 31 sites with a total of 155 units that resulted in a decrease in her monthly headaches to four migraine headache days per month and four mild, non-migrainous headache days per month. ${ }^{12}$ Her nonmigraine headaches were described as being mild in nature located diffusely over the forehead with no aura and no other symptoms such as nausea, photophobia, or phonophobia.

As her spasticity had markedly improved with intrathecal baclofen, ziconotide was added to help her lower extremity neuropathic pain. Two months following initiation of lowdose ziconotide ( $1 \mu \mathrm{g} /$ day), the patient noted both neuropathic pain improvement and complete resolution of migraine headaches resulting in only two or three mild, non-migraine headache days per month with zero migraine headaches (Table 1). She has not used any triptans since ziconotide was added to her intrathecal pump.

The intrathecal catheter tip is located at the bottom of the T9 vertebral body. Her total daily intrathecal therapy consisted of $89.88 \mu \mathrm{g}$ of baclofen and $1.0068 \mu \mathrm{g}$ of ziconotide. She had a continuous infusion rate of baclofen at $1 \mu \mathrm{g} / \mathrm{h}$ and ziconotide at $0.0112 \mu \mathrm{g} / \mathrm{h}$. Additionally, she had a flex dosing parameter that was initially started when she was on baclofen monotherapy for her spasticity. As this dosing schedule was quite effective for her spasticity, it was not altered when ziconotide was added to her pump. With the flex dosing, she received $10.98 \mu \mathrm{g}$ of baclofen and $0.1230 \mu \mathrm{g}$ of ziconotide every 4 hours for a total of six doses per day. The flex doses are given over a period of 2 minutes.

Given her marked improvement with low-dose ziconotide, no dose escalation was required. She has now been stable with this dosing regimen for the last 8 months. During her baseline and Botox treatment periods, the patient was still using NSAIDs and triptans. She has not used any triptans once she was started on ziconotide and has only occasionally used NSAIDs for her non-migrainous headaches.

Table I Patient's migraine headache patterns through various treatments

\begin{tabular}{llll}
\hline & Baseline & Botox & Ziconotide \\
\hline Migraine headache days per month & 22 & 4 & 0 \\
$\begin{array}{l}\text { Non-migraine headache days } \\
\text { per month }\end{array}$ & $3-4$ & 4 & $2-3$ \\
\hline
\end{tabular}

Notes: During her baseline and Botox treatment periods, the patient was using NSAIDs and triptans. She has not used any triptans once she was started on ziconotide and has occasionally used NSAIDs for her non-migrainous headaches.

Abbreviation: NSAIDs, nonsteroidal anti-inflammatory drugs. 


\section{Discussion}

This case presents an incidental discovery of ziconotide treatment resulting in complete resolution of chronic headaches with migraine features. This patient's intrathecal dosing utilized a dosing strategy of scheduled flex doses every 4 hours such that the $1 \mu \mathrm{g} /$ day dose of ziconotide was reached. This dosing strategy for ziconotide was based on the dosing strategy for baclofen. She had superior spasticity relief from flex dosing of baclofen versus simple continuous dosing despite equivalent total daily dosages of 88-90 $\mu \mathrm{g}$ of baclofen per day. While this patient did have a significant migraine reduction from Botox therapy (Table 1), she did continue to have some form of headaches for nearly one-third of each month, and notably, still had debilitating migraines on 4 days per month. Only with the intrathecal baclofen-ziconotide combination did she achieve zero migraine headaches with only a few non-migrainous headaches per month.

Ziconotide has been studied in a variety of pain syndromes, but it has never been evaluated for migraine headache management. ${ }^{13-15}$ Although there are no case reports for migraine headaches, an extensive literature search produced two isolated case reports of trigeminal neuralgia improving with intrathecal ziconotide. In one case, a 50-year-old female was started on intrathecal ziconotide that was slowly increased from $0.33 \mu \mathrm{g} /$ day to $6.3 \mu \mathrm{g} /$ day. Her pain score decreased from $9 / 10$ to $3-4 / 10$. She was then continued on $3.9 \mu \mathrm{g} /$ day and had minimal pain at 5 -month follow-up. ${ }^{16}$

In the other case, a 59-year-old female had a single-shot ziconotide trial of $1 \mu \mathrm{g}$ at T12-L1 that resulted in a decrease in her trigeminal neuralgia pain from $9 / 10$ to $6 / 10$. She then had ziconotide placed into her morphine/clonidine pump at a rate of $1 \mu \mathrm{g} /$ day. ${ }^{17}$ Our case represents the first case of migraine improvement with intrathecal ziconotide.

Ziconotide is an N-type voltage calcium channel blocker originally developed as SNX-111. Ziconotide works by blocking presynaptic $\mathrm{N}$-type voltage-sensitive calcium channels within laminae I and II of the dorsal horn of the spinal cord. This suggests that ziconotide achieves its effect by blocking signal propagation from primary afferents to ascending pathways. ${ }^{12}$ In our patient, the intrathecal catheter tip is located at the bottom of the T9 vertebral body. The hydrophilic nature of the ziconotide molecule may be allowing it to spread through the cerebrospinal fluid and block nociceptive transmission from higher neurons. In fact, another patient with head/ neck pain from trigeminal neuralgia pain was successfully treated with ziconotide at the T12-L1 level suggesting that the catheter tip position may not influence the therapeutic role in symptom management. ${ }^{17}$
Ziconotide as a treatment for chronic migraine headache represents a possible avenue for those patients who do not respond well to traditional therapies. While Botox does help many patients, there are those who either do not receive the full 12 weeks of relief or continue to have debilitating headaches, albeit at a decreased frequency, throughout its efficacy period. These patients stand to gain the most from any potential new treatment development. Since chronic migraine sufferers have a markedly increased level of daily functional impairment and health care utilization compared to episodic migraineurs, finding effective treatments for these patients is imperative..$^{3-5}$

Questions remain regarding ziconotide's effects in this patient. Where in the central nervous system is the drug mediating this effect? Is the effect a result of the ziconotide-baclofen dual therapy? Does the flex dosing pattern contribute? Is it functioning in a preventive capacity or aborting migraines as soon as they begin?

Future studies will need to examine this phenomenon and to gather further cases to see if this therapeutic efficacy can be replicated - either in other patients with similar migraine features or even in patients with different comorbidities or headache types. We may need to find an optimal trial dose or alternative delivery method outside of intrathecal administration if possible. Future work may also consist of dosing strategies of intrathecal ziconotide trials (single dose versus continuous infusion trial) or optimal catheter tip location in patients with migraine headaches refractory to medication and Botox therapy.

\section{Conclusion}

This case presents a patient having complete resolution of her chronic migraine headaches for a period of 8 months with low-dose intrathecal ziconotide when other more traditional treatments only minimized her symptoms. With further study, we hope to evaluate this phenomenon further and potentially apply this treatment to other patients in the future.

\section{Disclosure}

The authors have no conflicts of interest to report.

\section{References}

1. Lipton RB, Bigal ME, Diamond M, Freitag F, Reed ML, Steward WF. Migraine prevalence, disease burden, and the need for preventive therapy. Neurology. 2007;68(5):343-349.

2. Headache Classification Committee of the International Headache Society (IHS). The international classification of headache disorders, 3rd edition (beta version). Cephalalgia. 2013;33(9):629-808.

3. Buse DC, Manack A, Serrano D, Turkel C, Lipton RB. Sociodemographic and comorbidity profiles of chronic migraine and episodic migraine sufferers. J Neurol Neurosurg Psychiatry. 2010;81:428-432. 
4. Bigal ME, Serrano D, Reed M, Lipton RB. Chronic migraine in the population: burden, diagnosis, and satisfaction with treatment. Neurology. 2008;71(8):559-566.

5. Munakata J, Hazard E, Serrano D, et al. Economic burden of transformed migraine: results from the American Migraine Prevalence and Prevention (AMPP) Study. Headache. 2009;49(4):498-508.

6. Gilmore B, Michael M. Treatment of acute migraine headache. Am Fam Physician. 2011;83(3):271-280.

7. Khalil M, Zafar HW, Quarshie V, Ahmed F. Prospective analysis of the use of OnabotulinumtoxinA (BOTOX) in the treatment of chronic migraine; real-life data in 254 patients from Hull, UK. J Headache and Pain. 2014;15:54.

8. Aurora SK, Gawel M, Brandes JL, Pokta S, VanDenburgh AM. Botulinum toxin type A prophylactic treatment of episodic migraine: a randomized, double-blind, placebo-controlled exploratory study. Headache. 2007;47(4):486-499.

9. Binder WJ, Brin MF, Blitzer A, Schoenrock LD, Pogoda JM. Botulinum toxin type A (BOTOX) for treatment of migraine headaches: an open label study. Otolaryngology. 2000;123(6):669-676.

10. Vitale V, Battelli D, Gasperoni E, Monachese N. Intrathecal therapy with ziconotide: clinical experience and considerations on its use. Minerva Anestesiol. 2008;74:727-733.

11. Bowersox SS, Gadbois T, Singh T, Pettus M, Wang YX, Luther RR. Selective N-type neuronal voltage-sensitve calcium channel blocker, SNX111 , produces spinal antinociception in rat models of acute, persistent and neuropathic pain. J Pharmacol Exp Ther. 1996;279:1243-1249.
12. Dodick DW, Turkel CC, DeGryse RE, et al; PREEMPT Chronic Migraine Study Group. OnabotulinumtoxinA for treatment of chronic migraine: pooled results from the double-blind, randomized, placebocontrolled phases of the PREMPT clinical program. Headache. 2010;50(6):921-936.

13. Wallace MS, Charapata SG, Fisher R, et al; The Ziconotide Nonmalignant Pain Study 96-002 Group. Intrathecal ziconotide in the treatment of chronic non-malignant pain: a randomized, double-blind, placebocontrolled clinical trial. Neuromodulation. 2006;9:75-86.

14. Staats PS, Yearwood T, Charapata SG, et al. Intrathecal ziconotide in the treatment of refractory pain in patients with cancer or AIDS: a randomized controlled trial. J Am Med Assoc. 2004;291:63-70.

15. Rauck RL, Wallace MS, Leong MS, et al; Ziconotide 301 Study Group. A randomized, double-blind, placebo-controlled study of intrathecal ziconotide in adults with severe chronic pain. J Pain Symptom Manage. 2006;31:393-406.

16. Lux EA. Case report: successful treatment of a patient with trigeminal neuropathy using ziconotide. Anesthesia Analgesia. 2010;110(4): 1195-1197.

17. Michiels WB, McGlthlen GL, Platt BJ, Grigsby EJ. Trigeminal neuralgia relief with intrathecal ziconotide. Clin J Pain. 2011;27:352-354.
Journal of Pain Research

\section{Publish your work in this journal}

The Journal of Pain Research is an international, peer-reviewed, open access, online journal that welcomes laboratory and clinical findings in the fields of pain research and the prevention and management of pain. Original research, reviews, symposium reports, hypothesis formation and commentaries are all considered for publication.

\section{Dovepress}

The manuscript management system is completely online and includes a very quick and fair peer-review system, which is all easy to use. Visit http://www.dovepress.com/testimonials.php to read real quotes from published authors. 